\title{
The ethical dangers and merits of predictive policing
}

\author{
Moish Kutnowski
}

\begin{abstract}
Predictive policing is an emerging law enforcement technique that uses data and statistical analysis to aid in the identification of criminal activity. Its intention is to proactively reduce crime by providing police forces with likely areas of high risk variables. While this is a noble pursuit, every new tool must be accompanied by the ethical considerations of its potential consequences. Predictive policing is still in its infancy, borne from crime analysis and big data; however, the Western criminal justice system in the traditional sense is a reactive institution with a diverse history. The use of predictive policing presents a new challenge for law enforcement in that it allows for a divergence from the distinct reality of modern policing. Using the United States as an example of the dangers and flaws of predictive policing as a discretionary tool used to justify questionable processes and biases, this paper will analyze the potential opportunity that predictive policing and new holistic forms of law enforcement and community safety initiatives can use in partnerships with communities and policy makers.
\end{abstract}

Key Words Predictive policing; big data; community safety; technology; policy planning; ethical policing; collaboration.

Journal of CSWB. 2017 Mar;2(1):13-17

www.journalcswb.ca

\section{INTRODUCTION}

Predictive policing is a relatively new phenomenon borne from Big Data analytics and trend forecasting. Big Data is the collection of large and complex datasets that are more accessible due to modern advanced technologies. In application, predictive policing uses analytical techniques on Big Data to detect probable criteria for police via statistical prediction (Perry, 2013). The larger conversation revolving around Big Data from a consumer and marketing perspective is highly scrutinized for privacy and accuracy concerns. This scrutiny becomes quickly critical with regards to predictive policing; law enforcement groups generally consider it a boon, while civil liberty groups generally consider it a bane. This paper will outline some of the ethical considerations vis-àvis the dangers and merits of predictive policing, given the limited information available in this evolving field.

There are some basic assumptions about how predictive policing is perceived that must be considered initially from a common, but not exhaustive, standpoint. There is a distinct bias against using data analytics to enforce a rule of law, whereas data analytics for the purposes of health, marketing, and economic development are generally supported. The assumption is that policing, and/or the activities therein, are fundamentally different from other activities. The normative paradigm would then be the divide between encouragement in community initiatives (like health and economics) and commandment (like policing). However, that could extend further within a realist context; the ability to enforce the rule of law is fundamental to social cohesion and rests solely in the state. While this may form the basis of a realist's perspective, an alternative perspective derived from a humanist's consideration would indicate that policing by its very nature rests outside of the social boundaries; it is unique only to policing. It would be antithetical for policing to conform to a universal maxim as it is responsive to state of nature behaviour within the confines of civil society.

The actual statistical model used in predictive policing depends on the Gaussian function as an integral kernel (Rosser and Cheng, 2016). This function acts as a probability estimate with limited and random variables, such as regional information, in order infer patterns, such as crime. While the use of statistical probabilities is ubiquitous in industry, it provides a questionable benefit for law enforcement. The difficulty with statistics for prediction, and Gaussian probability specifically, is its vulnerability to spurious variables which undermine the fundamental premise of predictability (Taleb, 2007).

The promise of predictive policing is alluring because it promises preventative measures, but in reality the justice system (and law enforcement) is reactive, which does not mean that community safety or policing necessarily is as well. 
The focus on retributive justice ignores the fact that crime can be prevented by addressing root causes that are often "third variable problems"-factors that are unconsidered in policing, but addressed in other areas of government. The base problem is that most social variables are codependent, and all variables are constantly in flux. Prediction it is still a useful tool and to disregard it completely would be to throw the baby out with the bathwater.

However, the problem of underutilizing a tool that could save lives, assuming predictive policing is a "tool" in the traditional sense, is just as egregious an ethical violation. Starting from the opposite end, that predictive policing will definitively reduce crime, the ideal law enforcement paradigm is to reduce crime without arrests. While there has been a drastic push to reduce petty and victimless offenses, the use of arrest quotas and the prison industrial complex in the United States, show a cognitive dissonance between the purity of policing as protective and the use of policing as a form of social control (and a blatant disregard for human rights) (Pelaez, 2008).

It is important to consider alongside this the repercussions in the Canadian context. Canada's justice system bears similarities to the United States, but is fundamentally different in terms of form and function. Britain's common law system evolved differently between the two countries. Whereas the US developed two systems recognizing the State and Federal interpretation of law, both beholden to the Constitution, Canada's federal system exclusively legislates, while the provincial and territorial courts execute. The US system also uses elected judges and an expanded use of juries, allowing for a more interpretive position of the law, while Canada's limited use of juries and appointed judges is more legally positivist. This is important as it indicates the different approaches that respective law enforcement must take to legally persecute criminals. Canada's lack of procedural flexibility (relative to the US), does not mean it is less innovative, but that it has different checks and balances than the more politically charged US system. As noted earlier, the use of the US as the blanket analysis is not to diminish the US systems or to collectively stereotype across North America, but illustrates the subtleties in the most extreme way in order to better observe and consider alternatives.

\section{METHODS}

\section{Case Study: the State of Georgia}

To better illustrate the potential for harm or good, and understood in the aforementioned context, the State of Georgia's (specifically Atlanta's) experience combating crime and its use of predictive policing will be analyzed as a case study.

Georgia is in the top three US states for the distribution of correctional population, adult correctional supervision rate, and total population supervised (Kaeble, Glaze, Tsoutis \& Minton, 2015). Georgia's estimated 2014 demographics show how African American rates of poverty are almost double the average state's crime rates, in addition to lower employment, lower rates of home ownership, and a large population of uneducated young men (US Census Bureau, 2014). The maps in Appendix A illustrate the greater crime concentration in the Hispanic and African American areas. This also correlates with housing affordability and school rankings; white areas have more expensive houses and better schools while the inverse is true for African American and Hispanic dominant regions (Trulia Maps, accessed 08/2016). Housing mobility and access to schooling coupled with perpetuated poverty in segregated areas puts those populations at a higher risk of crime, developmental stagnation, and perpetuated cycles of diminishing wellbeing (Kubisch, 2010).

In July 2013 the Atlanta Police Department (APD) piloted PredPol in several areas of the city. PredPol uses a proprietary statistical algorithm using municipal data to develop region specific predictions for higher probability of criminal activity. Using several zones identified by PredPol (African-American dominant areas with the highest crime rates in the state) and several zones without (as a control, region was unspecified), APD was able to definitively illustrate the benefit of PredPol via a significant reduction of crime rates compared to marginal rises in non-PredPol zones. Given these results, PredPol was rolled out city wide and became integrated into field officers daily patrol routines (Turner, Brantingham, \& Mohler, 2014).

\section{DISCUSSION}

\section{Analysis}

Applied through purely a personal lens, the use of this technology is more about how it seems to be used as a prop to confirm existing suspicion and less about its use of arbitrary corollaries between past and future events and. US history is littered with racial disparity in the justice system postemancipation. The use of convict leasing as a legal means of indentured servitude combined with the "Black Codes", a set of legislation throughout southern states that restricted the rights of African American into the 1930s (Cohen, 1991), the racially segregating Jim Crow laws which lasted until 1965, and the War on Drugs which disproportionately affected poor black populations (Human Rights Watch, 2000) all created a subclass that not only perpetuated crime in real terms, but also made it racially stereotyped (Gabbidon \& Greene, 2012). When you juxtapose the use of this technology as a form of reasonable suspicion with the current racial dialogue that has fueled ongoing debate on the targeting of ethnic and lower class populations by authorities and then look at the areas that PredPol and similar technologies considers "high risk", it becomes bleakly apparent that, regardless of the value this technology may have, it is primarily used as a questionable form of media protection under the cover of "advanced mathematics and computer learning".

The four pillars of punishment are retribution, deterrence, rehabilitation, and incapacitation (Dubber \& Hörnie, 2014). Retributive punishment intends to rebalance the suffering incurred by the victim or society by causing suffering in the offender in order to provide perceptual equilibrium. Deterrence is a preventative measure in which the threat of punishment is enough of a disincentive for criminal activity. Rehabilitation is a reformative measure wherein an offender's behaviour changes to prevent further infraction. Incapacitation is a macro mechanism where the offender is no longer able to commit further offense as a protection of society at the expense of the offender's rights/abilities/life (Dubber \& Hörnie, 2014). 
Unfortunately, given the embedded institutional biases both socially and judicially against ethnic and poor populations, the use of retributive justice perpetuates a vicious cycle of criminal behaviour and increasingly racial divides. Caucasian and affluent populations also commit crimes, but those crimes are generally distinct in nature and intention, and predictive policing will not be able to capture that distinction based on historical data. White and black non-violent crimes are nearly identical proportional to their respective populations; however, African American crime stats (i.e., arrests) are drastically disproportional for violent and drug charges. That is not to say there is no value in criminal data analytics; however, it should not be in the hands of police departments but urban planners and policy makers for the function of neighborhood rehabilitation and community development, not reinforced policing and retributive justice.

While I could not find any use cases for the application of predictive policing in urban planning or policy making, I will provide a hypothetical that illustrates my conception of how this would function.

\section{Hypothetical Use Case: Predictive Crime Analytics for Policy Planning}

Predictive policing illustrates how data can be used to influence a preferred outcome. The problem with the police using this information stems from the combination of a high rate of crime in areas that are generally poverty stricken, uneducated, and have above ethnic populations (Pager \& Shepherd, 2008). Now this is misleading as it correlates poverty, education, and ethnicity with crime; this is not a necessary truth. A city like Atlanta, which has clear ethnic divides within the city (as illustrated previously), only reinforces the notion that there is a necessary connection between ethnicity, education, and poverty with crime. The use of public space, however, can be used to repress and prevent crime, instead of reinforce notions of criminal behaviour.

The University of Pennsylvania, Perelman School of Medicine, published a study in 2013 that suggested that making public "green spaces" caused a decrease in total crime and gun assaults (Garvin, Cannuscio, \& Branas, 2013). This study looked at vacant lots that have spread across Philadelphia due to decreased industrial activity, and how the city's use of green areas reduced crime and made resident's attitudes more positive. By using predictive analytics, in partnership with other cities (to leverage scale economies and develop comprehensive analytics), cities can introduce green spaces, community gardens, and safe zones in high-impact regions (i.e., those outlined by PredPol). Depending on the variables, there are data that suggest ways to diffuse criminal activities; the use of zoning and land use has a proven relationship with crime rates (Anderson, MacDonald, Bluthenthal, \& Ashwood, 2012). For example, there is evidence to suggest that convenience stores with large parking lots are more likely to get robbed due to the lack of natural surveillance because of the distance between the store and pedestrians (Anderson et al., 2012). Similarly, housing projects with an externally visible elevator lobby had lower crime rates from those without a visible lobby. Commercial neighbourhoods have traditionally higher rates of crime than residential or mixed-use neighbourhoods, except in instances of small businesses which act as central nodes of crime watch and communication for the community (Anderson et al., 2012). Given the limited evidence, these theories have little support from policy and urban planners; however, creating opt-in policies would enable citizens to fight crime in an embedded, local, and cheaper fashion.

Predictive policing allows analysts to use historical data in conjunction with high-risk areas via a statistical lens to combine these two features; using historical data to proactively respond to predicted high-risk areas. This approach is currently used (albeit in a different form) by the Sidney and Lois Eskenazi Hospital's Prescription for Hope violence prevention program. The initiative encourages violent assault patients to enroll in the rehabilitative program before leaving the hospital. Analysts at the hospital have found that violent assault victims have a high likelihood of being return patients, and piloted this program to the residents of Marion County in 2009. The program features life skills training, teamwork development, and communication skills facilitated by a support specialist. The hospital has found a drop for violent injury recidivism of $30.8 \%$ to $4.6 \%$, as well as a direct annual savings of $\$ 380,000$ (Eskenazi Health Foundation, n.d.)

The potential benefits for predictive crime analytics informing a health initiative policy are boundless. Accessible care could be provided as a preventative measure, without burdening hospital infrastructure, by strategically placing modular care centres at risk communities (as identified by the predictive policing software), and having them interact within a network as a series of independent nodes. There are multiple roles that data analytics can participate in, and leveraging the interplay between the various facets of social life should be a policy priority.

Canadian law enforcement is providing a necessary service, and this is not to suggest otherwise. Instead it is to encourage the continued good-sense use of available tools with the understanding of the risk-potential balance. The danger that this paper is trying to consider is that the use of certain tools, not just predictive policing, in isolation is a challenge that law enforcement agencies must continue to consider. The use of certain tools with a community safety and well-being philosophy, alongside strategic partners and community stakeholders, provides the best harm reduction while supporting community wellness (Taylor, 2016).

\section{CONCLUSIONS}

At this stage, the entire field is inconclusive, but it is clear that there are new ways to reduce crime that are not necessarily based on traditional policing models. Utilizing tools in innovative ways is important to develop and evolve past the social barriers that have become institutionalized. Predictive policing is an extension of existing tools that our brains naturally adhere to in pattern recognition. However, the danger of using a new tool that is not well understood, does not develop past existing social problems, and reinforces embedded negative stereotypes rather than pushing past them, is a strong indicator that we as a society are using it the wrong way. When all you have is a hammer, everything looks like a nail.

\section{CONFLICT OF INTEREST DISCLOSURES}

The author states that there are no conflicts of interest. 


\section{REFERENCES}

Anderson, J. M., MacDonald, J. M., Bluthenthal, R., \& Ashwood, J. S. (2012). Reducing crime by shaping the built environment with zoning: An empirical study of Los Angeles. Un PA Law Rev., 161:699.

Cohen, W. (1991). At freedom's edge: Black mobility and the southern White quest for racial control, 1861-1915. Baton Rouge: Louisiana State University Press

Dubber, M. \& Hörnle, T. (2014). The Oxford handbook of criminal law. Oxford United Kingdom New York, NY: Oxford University Press.

Eskenazi Health Foundation. (n.d.) An insiders look: What is prescription for hope? Indianapolis, IN: Eskenazi Health Foundation. Retrieved Augus 31, 2016, from http://eskenazihealthfoundation.org/what-is-prescriptionfor-hope/

Gabbidon, S. L., \& Greene, H. T. (2012). Race and crime. Thousand Oaks, CA: Sage Publications.

Garvin, E., Cannuscio, C., \& Branas, C. (2012). Greening vacant lots to reduce violent crime: a randomised controlled trial. Injury Prevention, 19:198-203

Human Rights Watch. (2000). Punishment and prejudice: Racial disparities in the war on drugs. NY: Human Rights Watch.

Kaeble, D., Glaze, L., Tsoutis, A., \& Minton, T. (2015). Correctional populations in the United States, 2014. Bureau of Justice Statistics Bulletin (NC) 249513). Revised Jan. 21, 2016. Washington, DC: BJS.

Kubisch, A. (2010). Structures, strategies, actions, and results of community change efforts, in Anne C. Kubisch, Patricia Auspos, Prudence Brown, and Tom Dewar (eds). Voices from the field III: Lessons and challenges from two decades of community change efforts. Washington, DC: Aspen Institute

Pager, D., \& Shepherd, H. (2008). The sociology of discrimination: Racial discrimination in employment, housing, credit, and consumer markets. Ann Rev of Sociol., 34:181-209.

Pelaez, V. (2008). The prison industry in the United States: big business or a new form of slavery? Global Res., 3:8.

Perry, W. L., Mclnnis, B., Price, C., Smith, S., Hollywood, J.S. (2013). Predictive policing: The role of crime forecasting in law enforcement operations. Santa Monica, CA: Rand Corporation.

Rosser, G. \& Cheng, T. (2016). Improving the Robustness and Accuracy of Crime Prediction with the Self-Exciting Point Process through Isotropic Triggering". Applied Spatial Analysis, 9.

Taleb, N. N. (2007). The black swan: The impact of the highly improbable. New York: Random House.

Taylor, N.E. (2016). Your invitation to a new partnership in discovery and innovation. J Community Safety and Well-being, 1:1.

Trulia Maps. (n.d.). Crime in Atlanta. Retrieved August 31, 2016, from http:// www.trulia.com/local/atlanta-ga/tiles: I points:O_crime

Turner, G., Brantingham, J., \& Mohler, G. (2014). Technology Talk: Predictive policing in action in Atlanta, Georgia. The Police Chief, 81:72-74.

U.S. Census Bureau. (2014). 2014 American Community Survey-1 Year Estimates: Population Estimates. Washington, D.C.: U.S. Bureau of the Census. 


\section{APPENDICES}

\section{Appendix A: Atlanta, GA demographic and crime maps.}

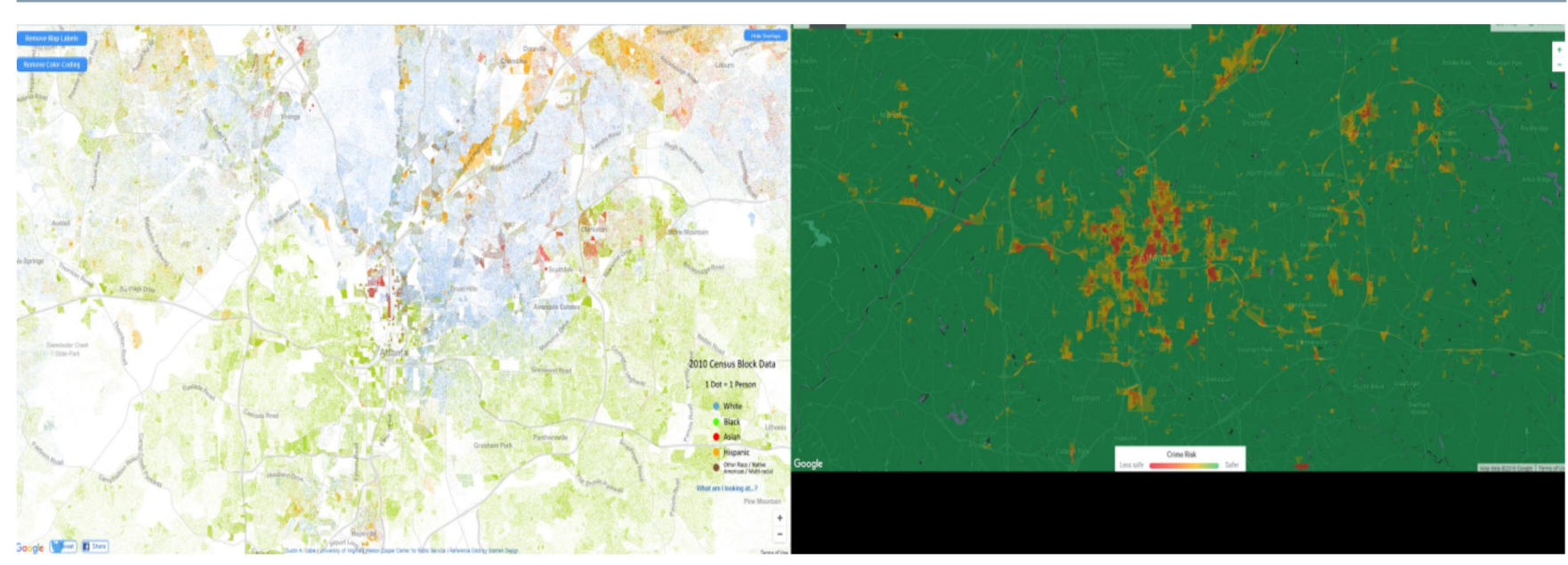

The map on the left illustrates the demographic breakdown (the stark segregation between African American populations [green] and Caucasian [white]). The map on the right shows crime breakdown as a heat map over the same area, with the highest concentrations being in African American neighborhoods. (Sources: https://demographics.virginia.edu/DotMap/index.html; http://www.trulia.com/local/atlanta-ga/tiles:lpoints:O_crime) 